\begin{tabular}{|c|c|c|}
\hline UFG & 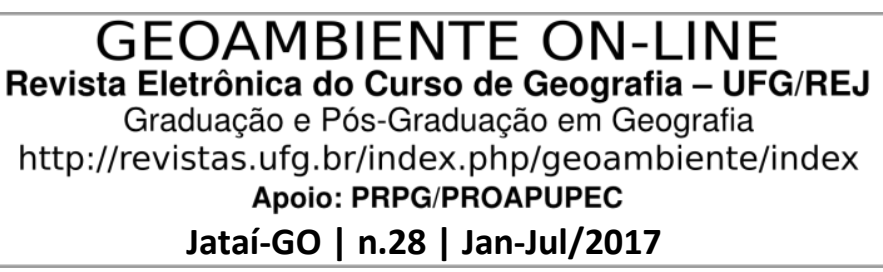 & $\begin{array}{l}\text { :GEO } \\
\text { İAMBIENTE } \\
\text { ISSN } 1679-9860\end{array}$ \\
\hline
\end{tabular}

\title{
CARACTERIZAÇÃO DE ÁREA DEGRADADA POR ATIVIDADE ANTRÓPICA
}

Andressa D’Agostin ${ }^{1}$, Andressa G. Glusczak², Laís Lavnitcki¹, Valter Antonio Becegato ${ }^{3}$ (1 - Universidade do Estado de Santa Catarina - UDESC, Mestranda em Ciências Ambientais, andressa.dg94@gmail.com; laisbruski_13@hotmail.com; 2 - Universidade Federal de Santa Maria - UFSM, Mestranda em Engenharia Civil, andressag.g@ hotmail.com; Universidade do Estado de Santa Catarina - UDESC, Docente, Doutor em Geologia Ambiental pela Universidade do Estado do Paraná - UFPR. valter.becegato@udesc.br)

Resumo: O presente trabalho objetivou oferecer alternativas de recuperação de uma área degradada localizada no município de Frederico Westphalen - RS que apresenta riscos de desmoronamento. A metodologia desenvolvida foi através de uma pesquisa exploratória em livros, artigos e documentos combinada à pesquisa de campo para observação de fatos e a realidade da área, que foram interpretados de forma a verificar qual a técnica de recuperação mais apropriada à situação. Ficou constatada a necessidade de recuperação física e biológica da área,bem como a estabilização dos taludes. Para isso, as técnicas de estabilização através de muro de gabiões ou muros de solo-pneus são as que melhor se adéquam, dadas as características da área, assim como sua recuperação biológica e física, através da revegetação com plantio de leguminosas e/ou espécies nativas para estabilização do solo, melhor infiltração da água e aumento das atividades biológicas, tendo-se assim um controle sobre a erosão, melhoramento dos aspectos paisagísticos e estéticos, sem comprometer o uso futuro da área.

Palavras-chave: Estabilização de talude, Revegetação, Recuperação física e biológica.

\section{PROPOSAL FOR RECOVERY OF AREA DEGRADED BY ANTHROPIC ACTIVITY}

\section{ASSOCIATED}

Abstract: This research aims to analyze means to recover a degraded area, located in Frederico Westphalen - Brazil, which has great risks of landslides, being suggested ways to prevent its aggravating condition. Chosen methodology involved exploratory research in books, articles and documents combined to fieldwork in order to observe facts and the area

Artigo recebido para publicação em 02 de Abril de 2017

Artigo aprovado para publicação em 15 de Junho de 2017 
reality, which were interpreted to evaluate the most appropriate recovery technique according to its situation. The need for the area physical and biological recovery was verified, as well as the slope stabilization. For this, retaining techniques such as gabionor soil-tires walls are the most adequate, considering the characteristics of the area, as well as its physical and biological recovery, through revegetation by planting native species and/or leguminous plants, better water infiltration and higher biological activity, which implies in erosion control, landscape and visual aspects improvement, not compromising the area's future usages.

Keywords: Slope stabilization, Revegetation, Physical and biologic recovery.

\section{PROPUESTA PARA LA RECUPERACIÓN DE UNA ZONA DEGRADADA POR LA ACTIVIDAD HUMANA}

Resumen: Este estudio tiene como objetivo ofrecer alternativas de recuperación para una zona degradada en el municipio de Frederico Westphalen - Brasil, sugiriendo la prevención de los agravantes, ya que presenta un grave riesgo de colapso. La metodología se dio por medio de una investigación exploratoria en libros, artículos y documentos combinados a investigación en campo a fin de observar factos y la realidad de la zona, que fueron interpretados de modo a verificar cual la técnica de recuperación más apropiada a la situación. La necesidad de la recuperación física y biológica de la zona y la estabilización de taludes fue constatada. Para tanto, las técnicas de estabilización con empleo de paredes de piedras enrejadas o suelo-neumáticos son las más adecuadas, dadas las características de la zona, así como la recuperación biológica y física a través de revegetación con leguminosas y/o especies nativas para la estabilización del suelo, mejor infiltración del agua y una mayor actividad biológica, funcionando de forma a controlar la erosión, mejorar el paisaje y la estética sin comprometer el uso futuro de la zona.

Palabras clave: Estabilización de taludes. Revegetación. Recuperación física y biológica.

\section{Introdução}

O solo é um componente essencial para a manutenção da sustentabilidade dos ecossistemas necessitando de um equilíbrio quanto suas características físicas, químicas, biológicas e visuais, sendo que a degradação dos solos se constitui como um prejuízo socioeconômico para as gerações atuais e futuras (CANDIDO FILHO et al., 2015). O Ministério do Meio Ambiente, por meio da Instrução Normativa no 5/2009 define área degradada como uma área onde a vegetação, flora, fauna e/ou solo foram total ou 


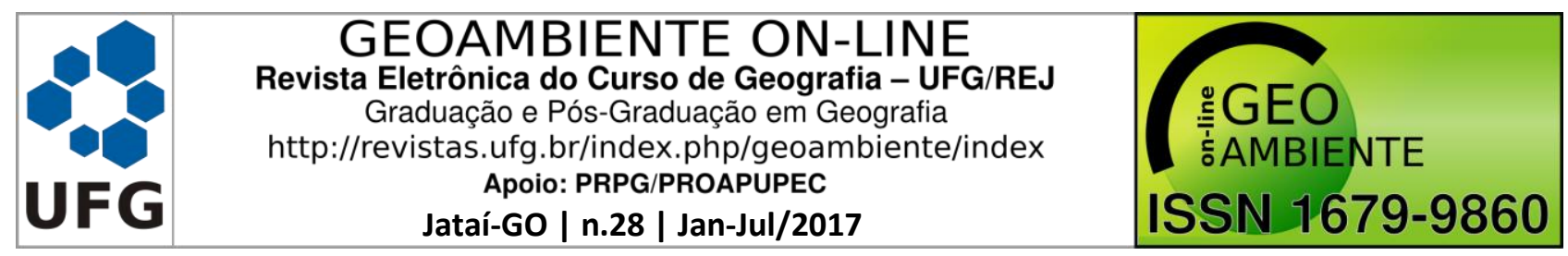

parcialmente destruídos, removidos e expulsos, tendo alterados sua capacidade produtiva e qualitativa (MMA, 2009).

Para Bezerra et al. (2006), o surgimento de áreas degradadas no Brasil tem aumentado ao longo dos anos, ocasionando inúmeros prejuízos ao meio ambiente, estando na maioria das vezes relacionado às atividades antrópicas sem planejamento. A degradação se caracteriza pela remoção do horizonte superficial do solo ocorrendo à perda de propriedades edáficas, favorecendo a atuação de processos erosivos, principal causa de degradação dos solos (MARX et al. 1995).

Tavares et al. (2008) citam que a erosão pode ser classificada em geológica e antrópica, de acordo com as atividades causadoras. A erosão geológica tem como causa as atividades geológicas ocasionadas pela água, ar, vento e gelo sobre a superfície terrestre, correspondendo a um processo natural, sem interferência humana. Já a erosão antrópica refere-se aos resultados da interferência humana sobre o ambiente, que vêm a se intensificar quando associada à erosão geológica.

Dentre as atividades do homem que causam a degradação do solo estão: o uso e ocupação do solo de forma desordenada e sem planejamento, com habitações em áreas de risco, desmatamento das cabeceiras de drenagem, além de obras de infraestrutura sem controle técnico, o que provoca alterações ambientais muitas vezes irreversíveis, facilitando a ocorrência de desastres naturais de grandes proporções(MEIRA et al., 2004).Contudo, áreas muito perturbadas não dispõem de capacidade de regeneração natural e, portanto, requerem o emprego de técnicas para sua recuperação, tanto estrutural quanto funcional (RODRIGUES \& GANDOLFI, 1996).

A Lei $n^{\circ} 9.985$ define recuperação como a restituição de um ecossistema ou de uma população silvestre degradada a uma condição não degradada, que pode ser diferente de sua condição original (Brasil, 2000); sendo a recuperação de áreas degradadas um dos objetivos da Lei $n^{\circ}$ 6.938, que institui a Política Nacional do Meio Ambiente (Brasil, 1981).

Com o aumento das áreas degradadas devido às atividades antrópicas desenvolvidas de forma desordenada, houve uma demanda de conhecimento gerada pela sociedade para reversão dos problemas, sendo criadas técnicas e estratégias de recuperação de áreas degradadas (VALCARCEL \& SILVA, 1997).

A recuperação de áreas degradadas se dá através de diversas técnicas de obras no terreno, como a construção de terraços, banquetas, caneletas, ou ainda, a implantação de espécies vegetais, podendo-se conduzir a recuperação. Porém, para que se possa escolher e 


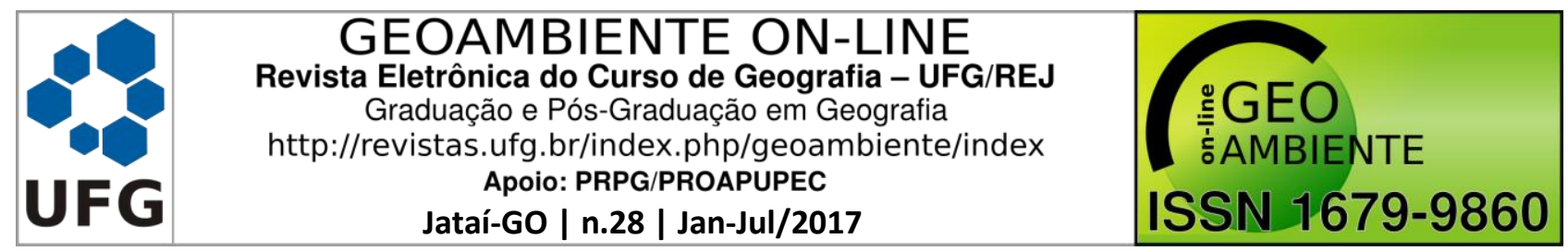

aplicar a técnica mais apropriada ao caso é necessário um plano de recuperação da área, juntamente a medidas de minimização da ação dos agentes erosivos e recuperação ambiental das áreas afetadas.

Este trabalho apresenta um estudo de recuperação de uma área que com riscos de desmoronamentos ocasionados por diferentes tipos de erosão, somadas ao agravante das atividades antrópicas realizadas no seu entorno, tendo-se também acúmulo de diversas classes de resíduos, o que pode agravar a questão da degradação e contaminação da área. Neste sentido o objetivo foi oferecer alternativas de recuperação para a área que se encontra degradada, sugerindo a prevenção de agravantes quanto aos riscos de desmoronamento.

\section{Material e Métodos}

Descrição da área de estudo

A área do presente estudo (Figura 1) está localizada na região fisiográfica do Alto Uruguai do estado do Rio Grande do Sul, município de Frederico Westphalen,às margens da rodovia Governador Leonel de Moura Brizola (BR 386).

Figura 1 -Localização da área de estudo

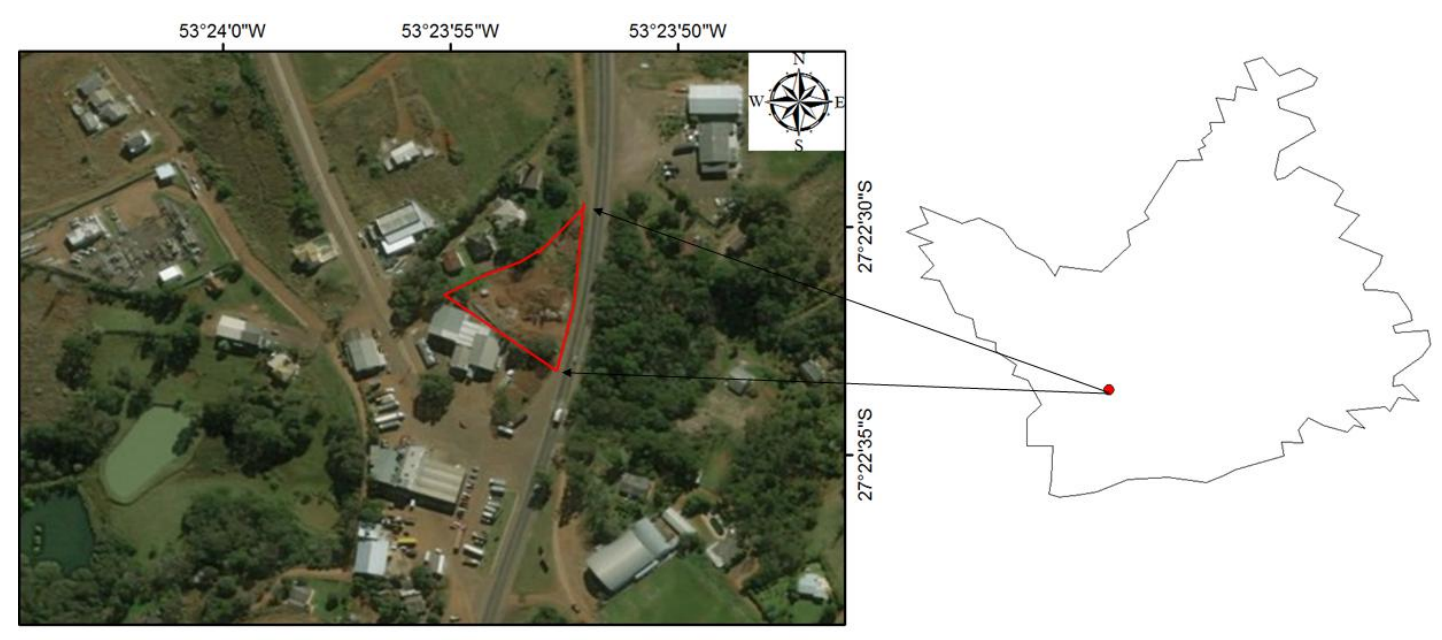

Fonte:Adaptado de Google Earth (2015).

No entorno da área está localizada uma revendedora de veículos usados, um hotel, posto de combustíveis, residências, além de margear uma das entradas de acesso à cidade de Frederico Westphalen estado do Rio Grande do Sul.

A geologia é composta pela Formação Serra Geral, cujo solo predominante é o Latossolo Vermelho distrófico(EMBRAPA, 2006), caracterizado por apresentar predominância de material mineral, bastante intemperizado, com horizonte diagnóstico B 


\begin{tabular}{|c|c|c|}
\hline U & $\begin{array}{c}\text { GEOAMBIENTE ON-LINE } \\
\text { Revista Eletrônica do Curso de Geografia - UFG/REJ } \\
\text { Graduacacão e Pós-Graduacão em Geografia } \\
\text { http://revistas.ufg.br/index.php/geoambiente/index } \\
\text { Apoio: PRPG/PROAPUPEC } \\
\text { Jataí-GO | n.28 | Jan-Jul/2017 }\end{array}$ & $\begin{array}{l}\text { :GEO } \\
\text { ISSN } 1679-9860\end{array}$ \\
\hline
\end{tabular}

latossólico, tendo capacidade em armazenar nutrientes e água, apresentando boa drenagem (PEDROSO NETO \& LOPES, 2009). O clima predominante é o Cfa, de acordo com Köppen $\&$ Geiger, (1928).

\section{Procedimentos metodológicos}

Efetuou-se campanhas in loco objetivando delimitar, fotografar, observar fatos, fenômenos e a realidade da área, que foram interpretados de forma a verificar qual técnica de recuperação melhor se adequa a situação, tendo-se por base vários trabalhos oriundos de uma ampla pesquisa bibliografia publicados entre os anos 2000 a 2015.

\section{Resultados e discussões}

Na Figura 2, observa-se a situação da área no ano de 2012, antes da construção de um muro de contenção dos taludes. Verifica-se a presença de vegetação nos taludes, bem como aporte de material de origem antrópica como resíduos da construção civil e outros além dos transportados por ação pluvial.

Figura 2 - Área de estudo em agosto de 2012 (polígono em vermelho) composta de material tecnógeno.

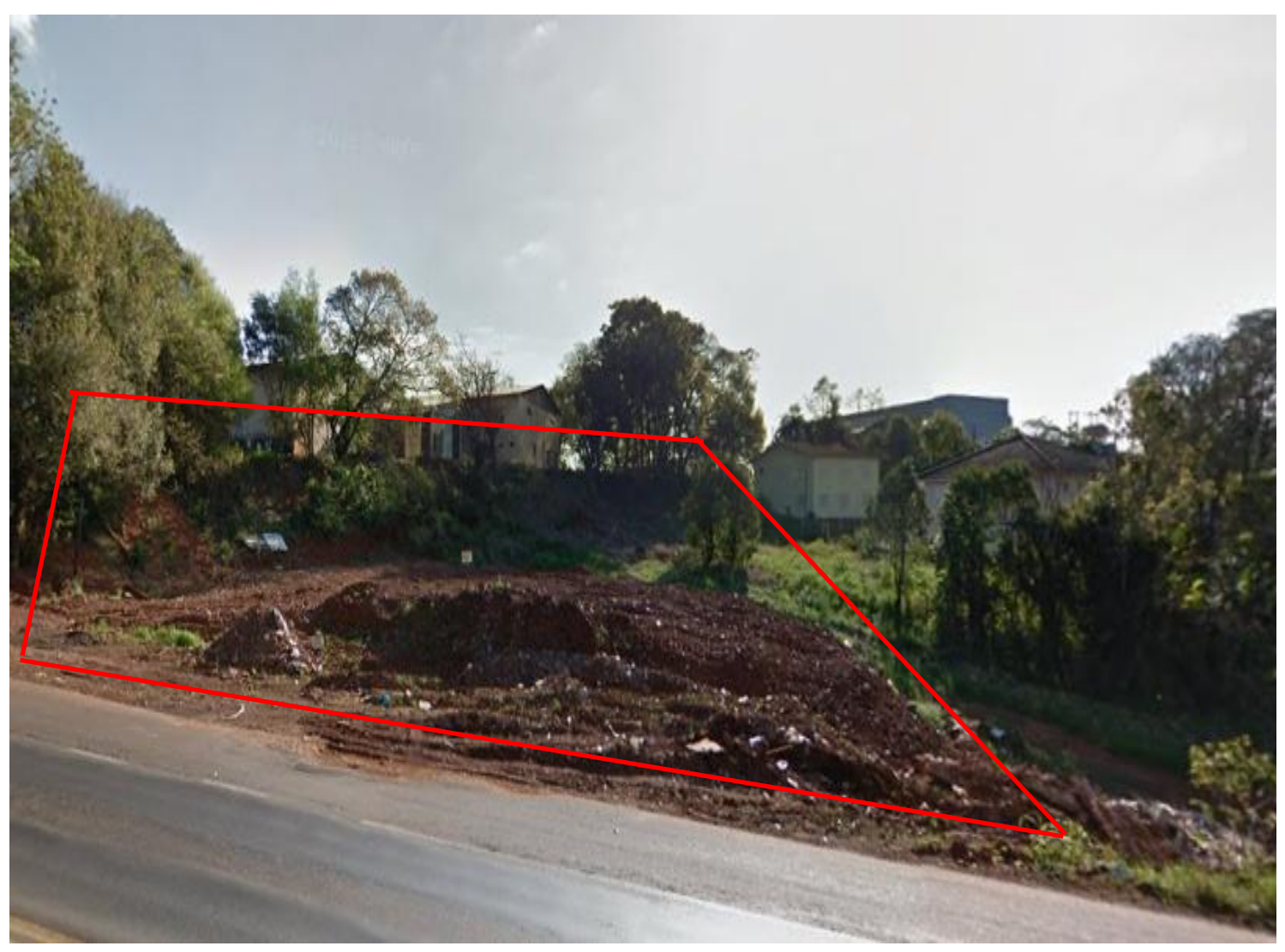

Fonte:Próprio autores. 


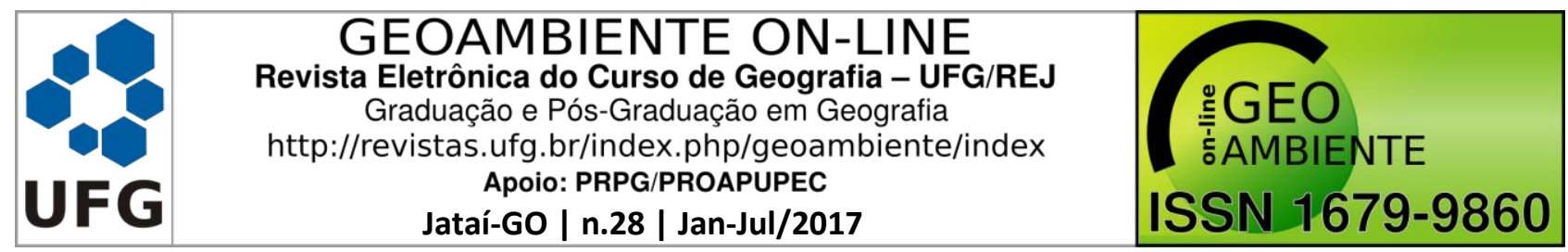

Nas vistorias realizadas no ano de 2014, pôde-se verificar que havia sido construído um muro de contenção, e que devido a um período intenso de chuvas ocorreu o desmoronamento de tal edificação, cuja contenção do mesmo e o sistema de drenagem não foram suficientes para conter o solo saturado por água, havendo consequentemente o colapso da referida construção(Figura 3).

Figura 3: Vestígios do muro de contenção.

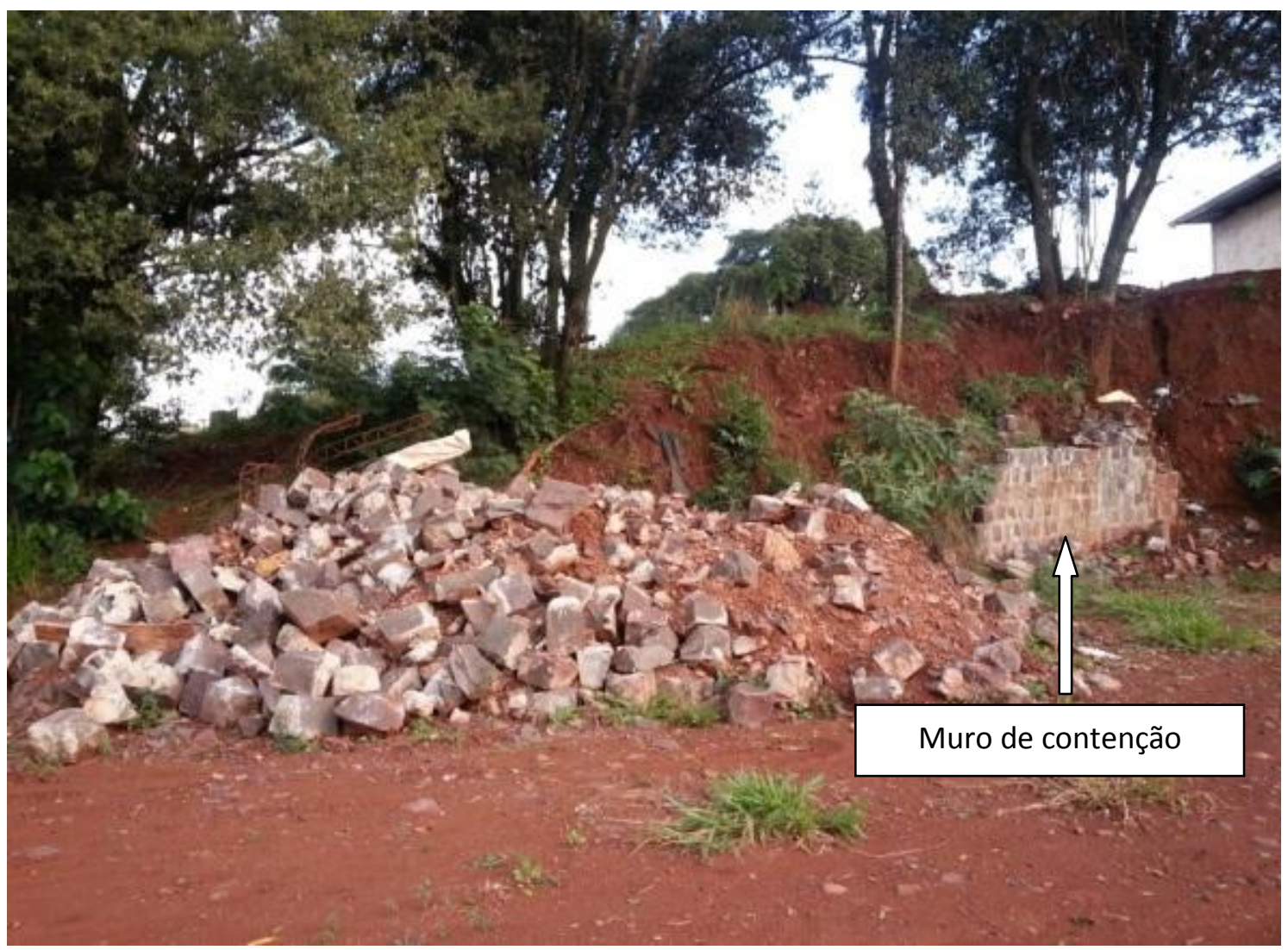

Fonte: Próprio autores.

Entre os anos de 2012 e 2014, houve um aumento considerável na quantidade de resíduos de construção civil que foram utilizados como sistema de drenagem assim como resíduos do muro; solo provenientes das atividades antrópicas e erosão hídrica e diminuição da vegetação (Figura 4).

A área apresentava riscos de desmoronamento e comprometimento das construções que se encontram no local, assim como a instabilidade da vegetação que apresenta raízes expostas pela falta de solo (Figura 5). Portanto, torna-se necessário a adoção de uma solução emergencial quanto à recuperação da área para minimização da ação dos agentes erosivos e diminuição da probabilidade de ocorrência de desastres naturais de grandes proporções. 


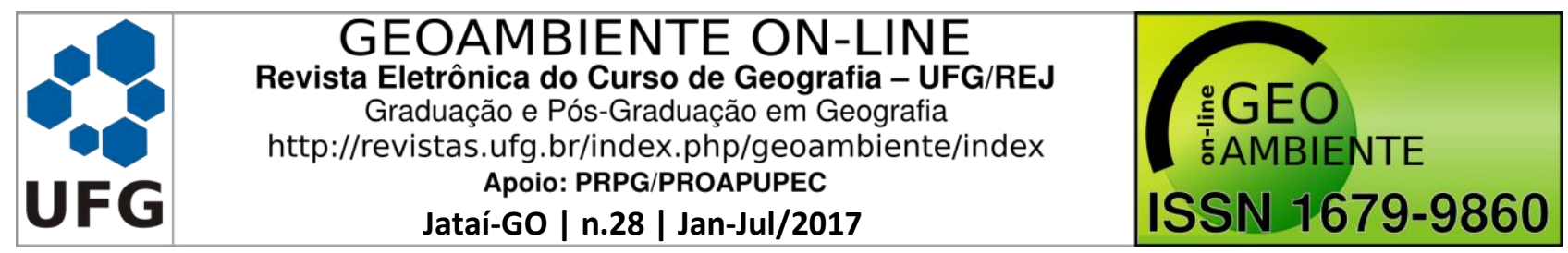

Figura 4. Depósitos tecnógenos.

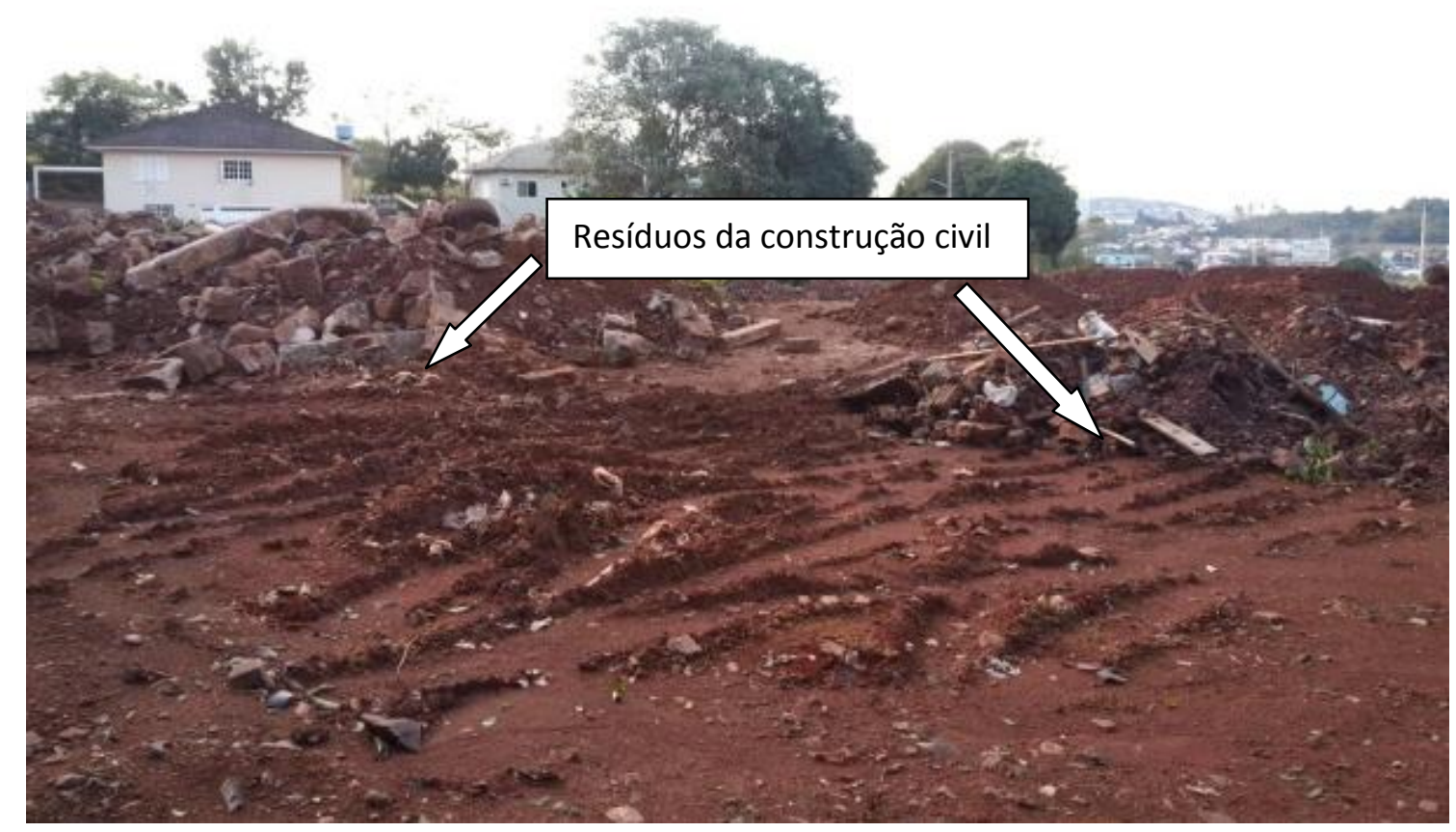

Fonte: Próprio autores.

Figura 5 - Situação da área no ano de 2014, evidenciando escorregamentos da massa de solos.

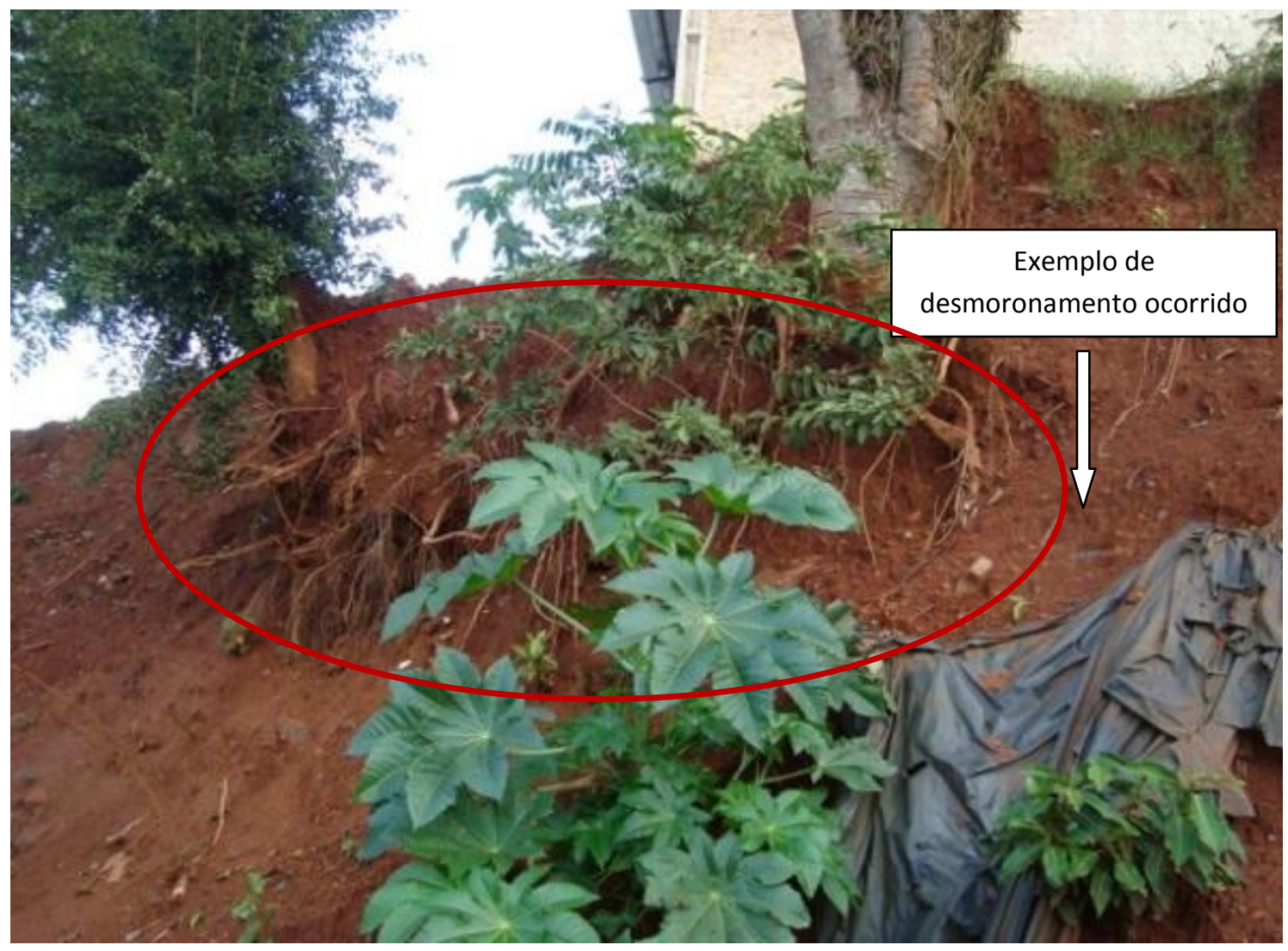

Fonte: Próprio autores. 


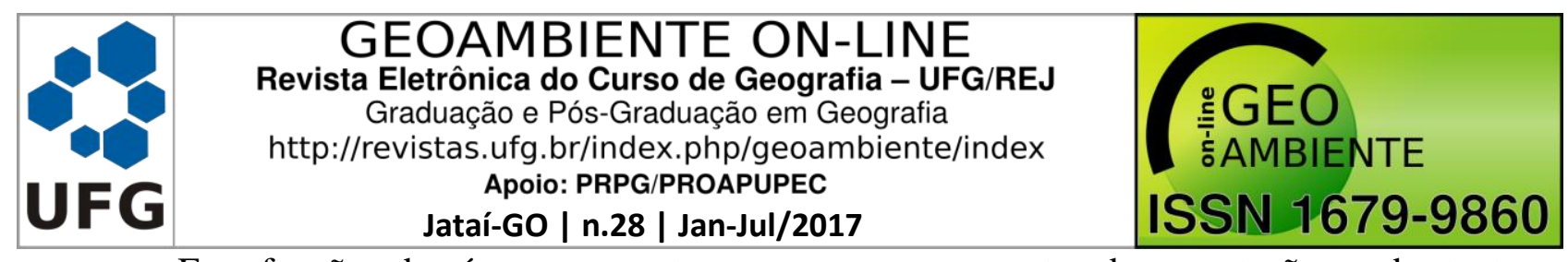

Em função da área apresentar pouco remanescente de vegetação e bastante interferência antrópica culminando em uma área de risco, não seria possível a regeneração natural. Assim, ocorre a necessidade de primeiramente realizar-se uma recuperação física para posterior revegetação e regeneração biológica.

A recuperação física compreende o preparo da superfície degradada, por meio da aplicação de tratamentos e técnicas que visam o controle de processos erosivos e o posterior estabelecimento de cobertura vegetal. Nesse contexto, inicialmente recomenda-se a limpeza da área, fazendo-se a remoção dos resíduos existentes.

A Lei $n^{\circ} 6.766$, que dispõe sobre o parcelamento do solo urbano, cita que ao longo das faixas de domínio público das rodovias, ferrovias e dutos, será obrigatória a reserva de uma faixa non aedificandi de quinze metros de cada lado, salvo maiores exigências da legislação específica (Brasil, 1979). Diante deste contexto, na área de estudo está proibida a edificação de qualquer atividade por situar-se próximo a BR 386.

Após a retirada dos resíduos que foram dispostos de forma inadequada, seria necessária a preparação do solo e adequação dos taludes. Para tanto, sugere-se a adição de material inerte para melhor estabilização dos taludes e posterior construção de outro muro de arrimo, conhecido também por muro de gravidade, podendo-se utilizar gabiões e/ou muro de solo-pneus.

Os gabiões podem ser do tipo caixa, manta ou saco, os quais são preenchidas com pedras dispostas manualmente, que apresentam como características principais a flexibilidade, permitindo que a estrutura se acomode a recalques diferenciais, e a permeabilidade (GERSCOVICH, 2010). De acordo com Silva \& Pires (2007), os gabiões são indicados para construção de muros de contenção, em qualquer ambiente, clima ou estação, sendo uma alternativa para projetos de recuperação, funcionando também como suporte para revegetação.

Quando implantados para contenção de talude, oferece resistência à movimentação deste ou à sua ruptura, reforçam uma parte deste talude, a fim de resistir os esforços tendentes a estabilização(LEITE, 2011).Porém, a implantação inadequada ou instabilidade do solo pode ocasionar rupturas. Para que isso não aconteça, devem ser feitas certas verificações de segurança contra tombamento, deslizamento, tensões excessivas e ruptura devido a estabilidade da área, sendo que esses fatores devem seguir os valores de segurança norteados pela Norma NBR n. 11682 (ABNT, 2009). 


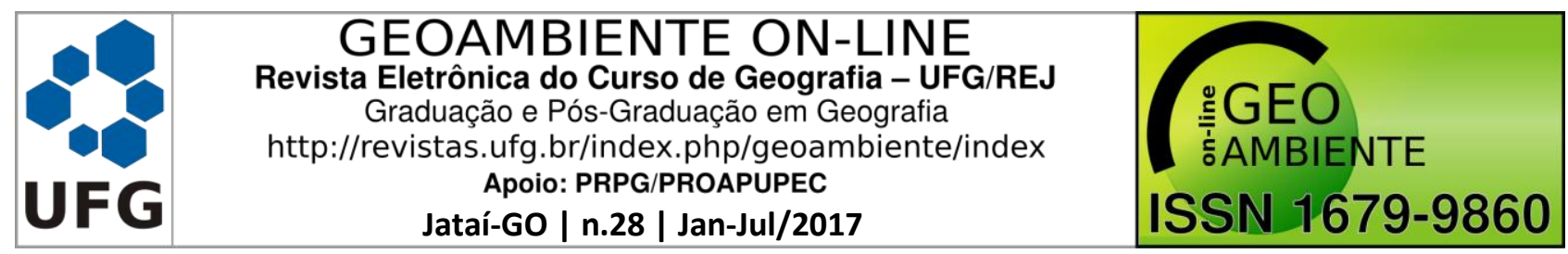

Roesner (2015) em estudo semelhante de estabilização de um talude na rodovia SC 435,verificou através de cálculos quanto aos fatores de segurança, que a área estava adequada para implantação da técnica de gabiões. Como o solo da presente pesquisa é o Latossolo Vermelho distrófico, profundo e combo a drenagem, também estaria em condições para implantação deste sistema de contenção, visto que, para Silva (2003), os muros de gabiões são auto drenantes, dependendo de qual seja o material de enchimento.

Os muros de solo-pneus são outra técnica semelhante aos gabiões, apresentando-se como muros de gravidade, construídos a partir do lançamento de camadas horizontais de pneus, amarrados entre si com corda ou arame e preenchidos com solo compactado, possuindo elevada resistência mecânica do material com o baixo custo, comparativamente aos materiais convencionais devido ao reaproveitamento (GERSCOVICH, 2010).

Este tipo de técnica apresenta um alto peso, sendo limitado a alturas inferiores a $5 \mathrm{~m}$ e à disponibilidade de espaço para a construção de uma base com largura da ordem de 40 a $60 \%$ da altura do muro, o que não seria problema para a área em estudo que apresenta espaço para construção da base e uma altura de aproximadamente 5 metros. No entanto, deve-se ressaltar que o muro de solo-pneus é uma estrutura flexível e, portanto, as deformações horizontais e verticais podem ser superiores às usuais em muros de peso de alvenaria ou concreto, devendo assim sua face externa ser revestida, para evitar não só o carreamento ou erosão do solo de enchimento dos pneus, como também o vandalismo (GERSCOVICH, 2010).

Tão importante quanto às obras de contenção do talude, são os sistemas de drenagem que devem ser combinados as técnicas de contenção. As drenagens mais utilizadas são as superficiais e/ou internos chamadas também de subsuperficiais (GERSCOVICH, 2010).

O sistema de drenagem superficial deve captar e conduzir as águas que caem sobre os taludes, levando-se em conta não só a área da região em estudo como também toda a bacia de captação (GERSCOVICH, 2010). A escolha do dispositivo depende das características da área quanto a ocupação, presença de vegetação, tipo de solo, geologia, tamanho do talude, entre outros fatores, podendo ser: canaletas transversais, canaletas longitudinais de descida (escada), dissipadores de energia, caixas coletoras, entre outros.

Os sistemas subsuperficiais ou internos atuam no controle das magnitudes de pressões de água e/ou na captação de fluxos que ocorrem no interior dos taludes e podem ser: drenos horizontais, trincheiras drenantes longitudinais, drenos internos de estruturas de contenção, filtros granulares e geodrenos (GERSCOVICH, 2010). Como medidas complementares, deve- 
se considerar a inserção de furos drenantes ou barbacãs para que as águas sejam drenadas para frente do muro.

Os muros com características drenantes como os gabiões dependendo do material de preenchimento, demandam instalação de filtro vertical na face interna do muro para que não haja o carreamento da fração fina do solo lançado para preencher o espaço entre o paramento da estrutura de contenção e o talude do terreno natural (COMPANHIA DE SANEAMENTO DO PARANÁ, 2008).

Após a contenção e estabilização dos taludes na área, pode-se realizar a revegetação, dando prioridade a alternativas mais econômicas e ecológicas. Para Tavares et al.(2008), uma opção ecológica interessante para áreas fortemente impactadas seria aquela em que se priorizam leguminosas fixadoras de nitrogênio $\left(\mathrm{N}_{2}\right)$ atmosférico de rápido crescimento tendose o recobrimento rápido do solo e contribuição dos níveis de carbono e nitrogênio. Além disso, ocorre nas raízes das leguminosas uma simbiose com bactérias (rhizobium) e fungos (micorrizas), acarretando em uma melhor absorção de nutrientes do solo e do ar, assim como uma maior absorção de água.

Observa-se, portanto, que dentre as vantagens da revegetação estão a promoção da estabilização do solo, melhora da infiltração, armazenamento da água da chuva e aumento das atividades biológicas do mesmo, ocasionados pela deposição de folhas, ramos, flores e o crescimento das raízes, criando condições propícias para o estabelecimento de outras espécies mais exigentes (secundárias). Schiavo et al. (2009), em um estudo de recuperação de área degradada através da revegetação,obteve resultados satisfatórios, onde as espécies arbóreas utilizadas afetaram significativamente as reações do solo e os teores de nutrientes de forma positiva.

Dessa forma, a presente área necessita de revegetação tanto na parte dos taludes como também no restante da mesma, o que facilitaria a infiltração da água e, consequentemente, acarretaria na diminuição do escoamento superficial e erosão do solo, aumentando a qualidade do solo e possibilitaria a diminuição da disposição de resíduos.

Vale lembrar que, qualquer que seja a técnica de estabilização de talude escolhida, deverá ser elaborado um projeto de recuperação da área com os estudos necessários, além de estar dentro dos padrões estabelecidos pela NBR n. 11682 (ABNT, 2009), que prescreve os requisitos exigíveis para o estudo e controle da estabilidade de encostas e de taludes.

\section{Considerações finais}


- A degradação ambiental oriunda da ação antrópica nem sempre pode ser evitada e, somado a isto, ocorrem fenômenos naturais que acabam por contribuir negativamente. Contudo, deve-se sempre buscar alternativas para minimizar ou mitigar tal degradação, de forma que o ambiente possa estar em equilíbrio.

- Do ponto de vista ambiental, é importante ressaltar que o manejo e a cobertura têm grande participação na variação das perdas de solo e deposição de sedimentos, mais ainda quando comparados com outros fatores como erodibilidade e declividade da área.

- Constatou-se que a área em estudo apresenta riscos de desmoronamento, comprometendo as atividades no seu entorno, sendo necessária a recuperação da área e estabilização dos taludes. Para isso, é possível que as técnicas de estabilização através de muro de gaviões ou muros de solo-pneus sejam as que melhores se adéquam, visto as características da área.

- Após a estabilização faz-se necessário a recuperação biológica, a revegetação com plantio de leguminosas e/ou espécies nativas. As vantagens da revegetação incluem a estabilização do solo, melhora da infiltração e armazenamento da água da chuva, assim como o aumento das atividades biológicas no mesmo acarretado pelo crescimento das raízes das plantas.

- Para o sucesso do trabalho de estabilização e reabilitação da área degradada em estudo, o relevo final deve estar estabilizado, tendo-se o controle quanto a erosão, melhoramento dos aspectos paisagísticos e estéticos sem comprometer o uso futuro da área e tendo a similaridade com o relevo original, devendo-se deixar quando possível o terreno plano ou com declividade inferior a $45^{\circ}$.

\section{Referências}

ASSOCIAÇÃO BRASILEIRA DE NORMAS TÉCNICAS. NBR 11682: Estabilidade de encostas.Rio de Janeiro, 33 p. 2009.

BEZERRA, F. B. OliveIRA, M.A.C.L; PEREZ, D.V; ANDRADE, A.G; MENEGUELLI, N.A. Lodo de esgoto em revegetação de área degradada. Pesquisa agropecuária brasileira, v. 41, n. 3, p. 469-476, 2006.

BRASIL. Lei n ${ }^{\circ}$ 6.766, de 19 de dezembro de 1979. Diário Oficial [da] República Federativa do Brasil, Poder Executivo, Brasília, DF, 20 dez. 1979. Disponível em: <http://www.planalto.gov.br/ccivil_03/leis/L6766.htm>. Acesso em: 22 jun. 2014. 


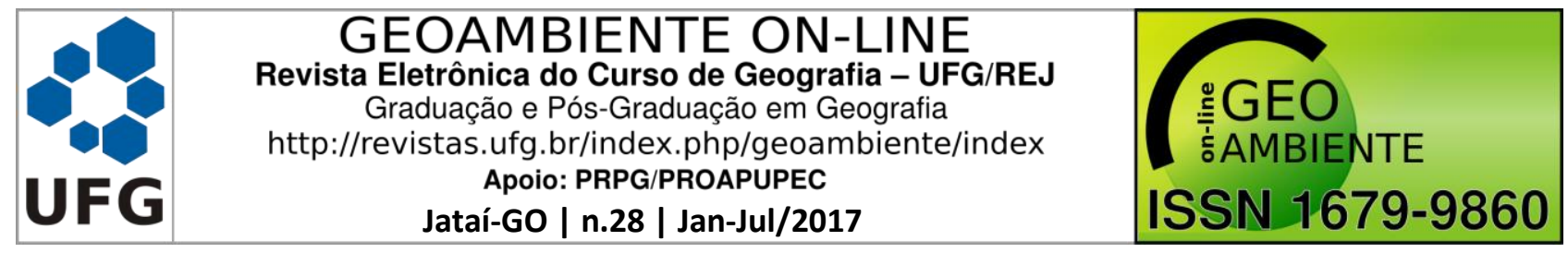

. Lei $\mathrm{n}^{\circ}$ 6.938, de 31 de agosto de 1981. Diário Oficial [da] República Federativa do

Brasil, Poder Executivo, Brasília, DF,2 set. 1981. Disponível em: <http://www.planalto.gov.br/ccivil_03/leis/L6938.htm>. Acesso em: 20 abr. 2017.

Lei $n^{\circ}$ 9.985, de 18 de julho de 2000. Diário Oficial [da] República Federativa do

Brasil, Poder Executivo, Brasília, DF, 19 jul. 2000. Disponível em: <http://www.planalto.gov.br/ccivil_03/leis/L9985.htm>. Acesso em: 20 abr. 2017.

COMPANHIA DE SANEAMENTO DO PARANÁ - SANEPAR. Manual de Obras de Saneamento: Obras de Contenção. Módulo 7, 2008. 11 p.

EMPRESA BRASILEIRA DE PESQUISA AGROPECUARIA - EMBRAPA. Sistema brasileiro de classificação de solos. 2.ed. Rio de Janeiro, Embrapa Solos, 2006. 306p.

CANDIDO FILHO, A; SANTOS, J.J.A; CANDIDO, B.C.A; PEREIRA.F.C; CRUZ,T.M.L. Recuperação de Áreas Degradadas.Congresso Técnico Científico da Engenharia e da Agronomia - $\quad$ CONTECC. 2015.2 Disponível em: http://www.confea.org.br/media/Agronomia_recuperacao_de_areas_degradadas.pdf. Acesso em 20 abr. 2017.

GERSCOVICH, D.M.S. Estruturas de Contenção: Muros de Arrimo.Faculdade de Engenharia da Universidade do Estado do Rio de Janeiro, Departamento de Estruturas e Fundações. Rio de Janeiro, 2010. 48p.

KÖPPEN, W.; GEIGER, R. Klimate der Erde. Gotha: Verlag Justus Perthes. 1928. Wall-map $150 \mathrm{~cm} \times 200 \mathrm{~cm}$.

LEITE, G. U. Análise custo-benefício de obras de contenção. Trabalho de Conclusão de Curso. Universidade Federal da Paraíba, 2011.

MARX, D. H.; BERRY, C. R.; KORMANIK, Paul P. Application of municipal sewage sludge in forest and degraded land. 1995.

MEIRA, A. S.; LEAO, J. L.; SANTOS, J. M. O Uso e ocupação do solo e a formação de voçorocas no município de Caetité - BA. In: VI Congresso Brasileiro de Geógrafos, 2004, Goiânia. Anais... Goiânia: AGB. Disponível em: < http:// www.igeo.uerj.br/VICBG2004/Eixo2/E2_015.htm >. Acesso em: 20 de abril 2017.

MINISTÉRIO DO MEIO AMBIENTE. Instrução Normativa $n^{\circ} 5$, de 8 de setembro de 2009.Disponível em: <http://www.redejucara.org.br/legislacao/in_5_2009_MMA.pdf>. Acesso em: 20 abr. 2017.

PEDROSO NETO, J.C.; LOPES, E.W. Caracterização física do Latossolo Vermelho distrófico da Fazenda Escola da FAZU. FAZU em Revista, n. 6, p. 11-52, Uberaba, 2009. 


\section{GEOAMBIENTE ON-LINE}

Revista Eletrônica do Curso de Geografia - UFG/REJ

Graduação e Pós-Graduação em Geografia

http://revistas.ufg.br/index.php/geoambiente/index

Apoio: PRPG/PROAPUPEC

Jataí-GO | n.28 | Jan-Jul/2017

๕GEO

¿́AMBIENTE

ISSN 1679-9860

RODRIGUES, R. R.; GANDOLFI, S. Recomposição de florestas nativas: princípios gerais e subsídios para uma definição metodológica. Ornamental Horticulture, v. 2, n. 1, 1996.

ROESNER, F. J. Retroanálise e proposta de estabilização de um talude da rodovia SC-435. Trabalho de conclusão de curso (Engenharia de Infraestrutura), 86 p. Universidade Federal de Santa Catarina, Joinville, 2015.

SCHIAVO, J. A; BUSATO, J.G; MARCO ANTONIO MARTINS, M.A; CANELLAS, L.P. Recovery of degraded areas revegeted with Acacia mangium and Eucalyptus with special reference to organic matter humification. Scientia Agricola, v. 66, n. 3, p. 353-360, 2009.

SILVA, D. A. ECV 5356 - Técnicas de construção civil I. 102p. Notas de aula - Universidade Federal de Santa Catarina, Florianópolis, 2003.

SILVA, P. J. da; PIRES, M. A. F. Renaturalização de rios, em áreas de trechos, urbanos com a aplicação de técnicas de bioengenharia em obras de engenharia hidráulica. XVII Simpósio Brasileiro De Recursos Hídricos \& VIII Simpósio De Hidráulica e Recursos Hídricos Dos Países De Língua Oficial Portuguesa. São Paulo, v. 1, p. 162-162, 2007.

TAVARES, S.R. L; ANDRADE, A. G; ROSSI, C. Q; CAPECHE, C. L; BALIEIRO, F. C; DONAGEMMA, G. K; CHAER, G. M; POLIDORO, J. C; MACEDO, J. R; PRADO, R. B; FERRAZ, R. P. D; PIMENTA, T. S Curso de Recuperação de Áreas Degradadas: a visão da Ciência do Solo no contexto do diagnóstico, manejo, indicadores de monitoramento e estratégias de recuperação.Rio de Janeiro: Embrapa Solos, 228 p. 2008.

VALCARCEL, R.; SILVA, Z. de S. A eficiência conservacionista de medidas de recuperação de áreas degradadas: proposta metodológica. Floresta, v. 27, n. 12, 1997. 